Contract No. and Disclaimer:

This manuscript has been authored by Savannah River Nuclear Solutions, LLC under Contract No. DE-AC09-08SR22470 with the U.S. Department of Energy. The United States Government retains and the publisher, by accepting this article for publication, acknowledges that the United States Government retains a non-exclusive, paid-up, irrevocable, worldwide license to publish or reproduce the published form of this work, or allow others to do so, for United States Government purposes. 


\section{Trimolecular Reactions of Uranium Hexafluoride with Water}

Maria C. Lind, Stephen L. Garrison, and James M. Becnel

Savannah River Nuclear Solutions LLC, Savannah River National Laboratory,

Aiken, South Carolina 29808

Trimolecular $\mathrm{UF}_{6}$ Hydrolysis 


\begin{abstract}
The hydrolysis reaction of uranium hexafluoride $\left(\mathrm{UF}_{6}\right)$ is a key step in the synthesis of uranium dioxide $\left(\mathrm{UO}_{2}\right)$ powder for nuclear fuels. Mechanisms for the hydrolysis reactions are studied here with density functional theory and the Stuttgart small-core scalar relativistic pseudopotential and associated basis set for uranium. The reaction of a single $\mathrm{UF}_{6}$ molecule with a water molecule in the gas phase has been previously predicted to proceed over a relatively sizeable barrier of $78.2 \mathrm{~kJ} \cdot \mathrm{mol}^{-1}$, indicating this reaction is only feasible at elevated temperatures. Given the observed formation of a second morphology for the $\mathrm{UO}_{2}$ product coupled with the observations of rapid, spontaneous hydrolysis at ambient conditions, an alternate reaction pathway must exist. In the present work, two trimolecular hydrolysis mechanisms are studied with density functional theory: (1) the reaction between two $\mathrm{UF}_{6}$ molecules and one water molecule, and (2) the reaction of two water molecules with a single $U_{6}$ molecule. The predicted reaction of two $\mathrm{UF}_{6}$ molecules with one water molecule displays an interesting "fluorine-shuttle" mechanism, a significant energy barrier of $69.0 \mathrm{~kJ} \cdot \mathrm{mol}^{-1}$ to the formation of $\mathrm{UF}_{5} \mathrm{OH}$, and an enthalpy of reaction $\left(\Delta \mathrm{H}_{298}\right)$ of $+17.9 \mathrm{~kJ} \cdot \mathrm{mol}^{-1}$. The reaction of a single $\mathrm{UF}_{6}$ molecule with two water molecules displays a "proton-shuttle" mechanism, and is more favorable, having a slightly lower computed energy barrier of $58.9 \mathrm{~kJ} \cdot \mathrm{mol}^{-1}$ and an exothermic enthalpy of reaction $\left(\Delta \mathrm{H}_{298}\right)$ of $-13.9 \mathrm{~kJ} \cdot \mathrm{mol}^{-1}$. The exothermic nature of the overall $\mathrm{UF}_{6}+2 \cdot \mathrm{H}_{2} \mathrm{O}$ trimolecular reaction and the lowering of the barrier height with respect to the bimolecular reaction are encouraging; however, the sizable energy barrier indicates further study of the $\mathrm{UF}_{6}$ hydrolysis reaction mechanism is warranted to resolve the remaining discrepancies between the predicted mechanisms and experimental observations.
\end{abstract}




\section{Introduction}

As nuclear energy is recognized as an effective means of producing electricity while limiting greenhouse gas emissions, a revival of the US nuclear industry may be expected. A recent study of nuclear fuel production has highlighted the lack of understanding of the fundamental reaction mechanisms that take place in nuclear fuel production on the molecular scale. ${ }^{1}$ Although nuclear fission (atomic radioactive decay) reactions are well-characterized, chemical reactions (in which bonds are formed and/or broken) involving uranium-containing species, (including $\mathrm{UF}_{6}, \mathrm{UO}_{2} \mathrm{~F}_{2}$, etc.) are not, and have proven to be difficult to study, both experimentally and computationally. For example, only recently have aerosol reactor experiments been undertaken to explore the minor changes in uranium processing conditions that affect the powder handling characteristics of the uranium dioxide $\left(\mathrm{UO}_{2}\right)$ product. ${ }^{1}$ Accordingly, improvements in the nuclear fuel production process will have a significant positive impact on the nuclear energy field.

One important production method for $\mathrm{UO}_{2}$ is the direct hydrolysis of $\mathrm{UF}_{6}$. This gasphase synthesis consists of two major steps, both at elevated temperatures for industrial conditions:

$$
\begin{aligned}
& \mathrm{UF}_{6}+2 \mathrm{H}_{2} \mathrm{O} \rightarrow \mathrm{UO}_{2} \mathrm{~F}_{2}+4 \mathrm{HF} \\
& \mathrm{UO}_{2} \mathrm{~F}_{2}+\mathrm{H}_{2} \rightarrow \mathrm{UO}_{2}+2 \mathrm{HF}
\end{aligned}
$$

The details of the $\mathrm{UF}_{6}$ hydrolysis reaction mechanism in the first step of this process remains poorly understood. This step and its kinetics have not been well-studied experimentally in recent years, likely due to the hazardous reaction products and radiological concerns. Only one experimental study ${ }^{2}$ has proposed a mechanism for the hydrolysis reaction; however, the 
proposed intermediate, uranium oxide tetrafluoride $\left(\mathrm{UOF}_{4}\right)$, has only been observed under extreme conditions. ${ }^{3-5}$

Although not specifically looking at the kinetics of the hydrolysis reaction, researchers have also investigated the hydrolysis reaction at or near ambient conditions. Several groups have studied $\mathrm{UF}_{6}$ hydrolysis at ambient and near-ambient conditions looking at particle growth and morphology. ${ }^{6-11}$ Kips and co-workers report no difficulties forming $\mathrm{UO}_{2} \mathrm{~F}_{2}$ particles by releasing $\mathrm{UF}_{6}$ gas into an atmosphere at room temperature with a relative humidity of approximately $60 \%{ }^{12}$ Additionally, Otey and Ledoux ${ }^{13}$ examined the product composition of the $\mathrm{UF}_{6}$ hydrolysis reaction as a function of water concentration, i.e., humidity, at elevated temperatures. In that work, they found only $\mathrm{UO}_{2} \mathrm{~F}_{2}$ product for $\mathrm{UF}_{6}: \mathrm{H}_{2} \mathrm{O}$ ratios less than about five and a new uranium oxyfluoride compound, $\mathrm{U}_{3} \mathrm{O}_{5} \mathrm{~F}_{8}$, for $\mathrm{UF}_{6}: \mathrm{H}_{2} \mathrm{O}$ ratios greater than approximately 55. No experiments were performed at ratios between these two values and no reaction mechanisms were proposed.

Fortunately, current computational chemistry methods are approaching engineering scale accuracy for actinide systems. ${ }^{14}$ Computational studies have reported equilibrium properties of $\mathrm{UF}_{6}$ and related uranium oxides and other uranium compounds, ${ }^{15-24}$ but relatively little research is available on the mechanism of hydrolysis. Computational results to date ${ }^{25-27}$ indicate that the gas-phase hydrolysis reaction between one $\mathrm{UF}_{6}$ molecule and one $\mathrm{H}_{2} \mathrm{O}$ molecule progresses via a reaction barrier of approximately $78.2 \mathrm{~kJ} \cdot \mathrm{mol}^{-1}\left(18.7 \mathrm{kcal} \cdot \mathrm{mol}^{-1}\right)$. This reaction barrier is not indicative of the rapid hydrolysis observed at ambient conditions. ${ }^{6-12,28}$ However, it is in agreement with the argon-matrix supported $\mathrm{UF}_{6}$ hydrolysis observations of Sherrow and Hunt, which indicate the bimolecular hydrolysis does not occur spontaneously at lower temperatures. ${ }^{29}$ 
These findings indicate there may be an alternate hydrolysis pathway besides the bimolecular $\mathrm{UF}_{6}+\mathrm{H}_{2} \mathrm{O}$ reaction step. The notion of an alternate hydrolysis pathway is further supported by the transition of $\mathrm{UO}_{2}$ particle morphology from spheres to platelets that has been observed in both production processes and laboratory experiments. ${ }^{1}$ Although $\mathrm{UO}_{2} \mathrm{~F}_{2}$ is only an intermediate in the production of $\mathrm{UO}_{2}$ nuclear fuels, its particle size and morphology are believed to determine the resulting $\mathrm{UO}_{2}$ particle properties. ${ }^{1}$ The abruptness in the morphology change indicates a switch in a fundamental mechanism rather than a gradual transition between competing physical processes. As the reaction is known to progress readily under ambient conditions, this alternate reaction pathway should have a reaction barrier of approximately $10 \mathrm{kcal} \cdot \mathrm{mol}^{-1}$ or less.

Although trimolecular reactions are rare, they have been shown to occur. ${ }^{30,31}$ In ambient, humid atmosphere, water clusters have been predicted ${ }^{32}$ and water dimers have been confirmed ${ }^{33}$ to exist at detectable, albeit low, concentrations $\left(\sim 0.1 \%\right.$ of total $\left.\mathrm{H}_{2} \mathrm{O}\right) .{ }^{34}$ It is possible the water dimer itself is a reactant and could start $\mathrm{UF}_{6}$ hydrolysis through an initiation-propagation mechanism. In this work, two trimolecular gas-phase hydrolysis reactions are studied using computational means: (1) the reaction between two $\mathrm{UF}_{6}$ molecules and one water molecule, and (2) that of two water molecules with a single $\mathrm{UF}_{6}$ molecule. The results discussed here more closely match experimental observations, and the improvement in the predicted energy barrier indicates that further study of the $\mathrm{UF}_{6}$ hydrolysis reaction mechanism may provide a satisfactory solution. 


\section{Computational Details}

Considerable progress has been made in the past decade toward improving the computational treatment of actinides. Methods including all-electron scalar relativistic approaches, the zeroth-order regular approximations (ZORA), ${ }^{35}$ the two-component third-order Douglas-Kroll-Hess (DK3) Hamiltonian, ${ }^{36,37}$ and relativistic effective core potentials (RECPs) $)^{38,39}$ have been developed that treat a significant portion of the relativistic effects for actinides and make the computations more tractable.

In this work, density functional theory (DFT) was used for all energy calculations, geometry optimizations, and harmonic vibrational frequency calculations. The Stuttgart energyadjusted, small-core (60 electrons treated as core, 32 as valence), RECP (SDD) ${ }^{39}$ was used for uranium. The associated SDD basis set ${ }^{40}$ was used for uranium, with the most diffuse function for each shell (each having an exponent of 0.005 ) removed from the basis in order to improve SCF convergence. ${ }^{16,41}$ Although the SDD RECP includes scalar relativistic effects, it neglects spin-orbit coupling. For uranium oxyfluorides, spin-orbit coupling has been estimated to contribute less than $\pm 5 \mathrm{kcal} \cdot \mathrm{mol}^{-1}$ to the computed energy, which is generally within both experimental and computational uncertainties. ${ }^{16}$ The fluorine, oxygen, and hydrogen atoms were represented using the $6-31++G(d, p)$ basis set. The hybrid functional B3LYP ${ }^{42,43}$ was used for all computations, along with an ultrafine numerical integration grid, as implemented in Gaussian 03 $(\mathrm{G} 03)^{44}$

The combination of a hybrid functional with the SDD small-core RECP has been found to be a reliable computational method for similar actinide systems. ${ }^{14,16,18,25,45-47}$ Ismail et al. found that B3LYP with a small-core RECP provided reliable results at low computational cost for the $\mathrm{UO}_{2}{ }^{2+}$ and $\mathrm{PuO}_{2}{ }^{2+}$ ions. ${ }^{47}$ For $\mathrm{UO}_{2}{ }^{2+}$ and several actinide hexafluorides, Han and Hirao 
found hybrid functionals provided reliable results, but the performance of GGA functionals was worse than the local density approximation for geometries and vibrational frequencies (and hence zero-point energy corrections). ${ }^{18}$ For vibrational frequencies, bond lengths, and bond dissociation energies for $\mathrm{UF}_{5}$ and $\mathrm{UF}_{6}$, Batista et al. found that hybrid functionals $\mathrm{PBE}^{48}$ (also known as PBE1PBE in G03) and B3LYP, with the SDD small-core RECP provided the best agreement with experimental data. ${ }^{14}$ Shamov et al. found hybrid functionals, when combined with a sufficiently large basis set, provided the best agreement with experimental thermochemistry and $\operatorname{CCSD}(\mathrm{T})$ bond strengths for a range of uranium oxyfluorides. ${ }^{16}$ Only for $\mathrm{U}=\mathrm{O}$ vibrational frequencies, which hybrid functionals consistently overestimated, were GGA functionals more appropriate. Previous work by two of the current authors suggests that B3LYP and PBE0 yield equivalent results $\left( \pm 2 \mathrm{~kJ} \cdot \mathrm{mol}^{-1}\right)$ for optimized geometries and reaction energies, barriers, and enthalpies for the bimolecular $\mathrm{UF}_{6}+\mathrm{H}_{2} \mathrm{O}$ hydrolysis reaction. ${ }^{25}$ These results were also within $\pm 6 \mathrm{~kJ} \cdot \mathrm{mol}^{-1}$ of the MP2 results. Iché-Tarrat and Marsden found the performance of hybrid functionals to be equivalent to or better than GGA functionals for vibrational frequencies and thermochemistry for several uranium systems. ${ }^{45}$ However, while thermochemistry calculations for both PBE0 and B3LYP were on par with experimental accuracy, PBE0 was found to be slightly better than B3LYP. As such, we also repeated the B3LYP calculations using PBE0 and found negligible changes in our reported geometries and calculated values.

\section{$\underline{2 \cdot \mathrm{UF}_{6}} \underline{+\mathbf{H}_{2}} \underline{\underline{\mathrm{O}}}$}

For the $2 \cdot \mathrm{UF}_{6}+\mathrm{H}_{2} \mathrm{O}$ reaction, eleven initial configurations of two $\mathrm{UF}_{6}$ molecules with one water molecule were chosen and optimized to identify candidates for the global minimum energy configuration. Two low-energy structures for the $\mathrm{UF}_{6}$ dimer were chosen for the starting 
structures, corresponding to (a) the dimer within the $\mathrm{UF}_{6}$ crystal structure with the shortest $\mathrm{U}-\mathrm{U}$ distance and (b) the minimum energy configuration for the $\mathrm{UF}_{6}$ dimer according to B3LYP/SDD/6-31G(d,p) computations. A water molecule was added to those two $\mathrm{UF}_{6}$ dimer configurations, in various orientations, with the oxygen atom oriented closest to the uranium in accordance with Sherrow and Hunt's analysis of the $\mathrm{UF}_{6}+\mathrm{H}_{2} \mathrm{O}$ FTIR spectra. ${ }^{29}$ Optimizations of the initial configurations located two structures, geometrically similar and having nearly the same energy. Four other local minima were found, but were approximately $5-10 \mathrm{~kJ} \cdot \mathrm{mol}^{-1}$ higher in energy. The structure with the lowest energy was used for the potential energy surface scans (Fig. 1). A relaxed potential energy surface scan was performed in order to locate possible transition states for the hydrolysis reaction. The shortest $\mathrm{U}-\mathrm{O}$ distance was incrementally decreased from 2.74 to $1.85 \AA$. After a maximum in energy as a function of $\mathrm{U}-\mathrm{O}$ separation was found, quadratic synchronous transit calculations (QST2 and QST3 calculations in G03) were run using the two local minima (pre-reactive and product complexes) as endpoints and the maximum energy configuration as an initial guess for the transition state structure (QST3). Fully unconstrained transition state optimizations using analytical Hessians were run, with the final results from the QST calculations used as the initial configurations. A single transition state with a U-O separation of $2.24 \AA$ was found, having only one imaginary vibrational frequency (Fig. 1).

\section{$\underline{\mathrm{UF}}_{6} \underline{+2 \cdot \mathrm{H}_{2}} \underline{\underline{\mathrm{O}}}$}

For the $\mathrm{UF}_{6}+2 \cdot \mathrm{H}_{2} \mathrm{O}$ reaction, optimizations to find likely pre-reactive complexes for the trimolecular reaction were started with a second water molecule placed at five different locations around the bimolecular $\mathrm{UF}_{6}+\mathrm{H}_{2} \mathrm{O}$ pre-reactive complex optimized in our earlier study. ${ }^{25}$ 
Notably, the addition of a second water molecule reduces the minimum predicted $\mathrm{U}-\mathrm{O}$ separation distance from approximately 2.8 to $2.6 \AA$ in the resulting pre-reactive complex candidate structures with the lowest energy. One-dimensional, relaxed potential energy surface scans were then performed for each resulting candidate configuration, with the shorter $\mathrm{U}-\mathrm{O}$ separation systematically reduced from 2.7 to $1.8 \AA$ (an approximate $\mathrm{U}=\mathrm{O}$ bond length). Two of the potential energy surface scans did not indicate likely transition state configurations with a maximum in energy with respect to the $\mathrm{U}-\mathrm{O}$ separation. The other three potential energy surface scans resulted in the same estimate for the transition state configuration. Again, QST2 and QST3 calculations were run in G03 using the two local minima as endpoints and the maximum energy configuration as an initial guess for the transition state structure. Fully unconstrained transition state optimizations using analytical Hessians were then run, with the final results from the QST

calculations used as the initial configurations. A single transition state with a $\mathrm{U}-\mathrm{O}$ separation of $2.24 \AA$ was located, and was confirmed to have only one imaginary vibrational frequency (Fig. 2).

\section{Results and Discussion}

$\underline{\mathbf{2} \cdot \mathbf{U F}_{6}} \underline{+\mathbf{H}_{2}} \underline{\underline{\mathrm{O}}}$

The hydrolysis reaction of two $\mathrm{UF}_{6}$ molecules with one water molecule is predicted to proceed through an interesting "fluorine-shuttle" mechanism, as indicated by both the structure (Fig. 1) and the vibrational mode of the imaginary frequency for the transition state. A "primary" $\mathrm{UF}_{6}$ accepts a hydroxyl group from the water molecule. The "spectator" $\mathrm{UF}_{6}$ molecule accepts a fluorine atom from the primary $\mathrm{UF}_{6}$ while it donates a fluorine to the proton of the water molecule to form hydrogen fluoride (HF). The estimated energy barrier for this mechanism is 
$69.0 \mathrm{~kJ} \cdot \mathrm{mol}^{-1}$, which is $9.2 \mathrm{~kJ} \cdot \mathrm{mol}^{-1}$ lower in energy than that of the bimolecular reaction (one $\mathrm{UF}_{6}$ and one $\mathrm{H}_{2} \mathrm{O}$ molecule) at the $\mathrm{B} 3 \mathrm{LYP} / \mathrm{SDD} / 6-31++\mathrm{G}(\mathrm{d}, \mathrm{p})$ level of theory. All energies reported herein are computed with the inclusion of zero point energy (ZPE) corrections unless otherwise noted. Although the trimolecular hydrolysis reaction is still endothermic, the addition of a second $\mathrm{UF}_{6}$ molecule lowers the energy barrier significantly (Table 1). This barrier reduction seems to result from the presence of the second $\mathrm{UF}_{6}$, which accepts a fluorine atom from the hydrolyzing $\mathrm{UF}_{6}$ while providing the fluorine atom to form $\mathrm{HF}$.

\section{$\underline{\mathrm{UF}}_{\underline{6}}+\underline{2} \cdot \mathrm{H}_{2} \underline{\mathrm{O}}$}

A notable feature of the transition state located for the $\mathrm{UF}_{6}+2 \cdot \mathrm{H}_{2} \mathrm{O}$ system (shown in Fig. 2) is the "proton-shuttling" of a hydrogen between the two water molecules. The water providing the hydrogen to the nascent $\mathrm{HF}$ accepts one hydrogen from the water that is reacting with the $\mathrm{UF}_{6}$ to form $\mathrm{UF}_{5} \mathrm{OH}$. Mulliken charge analysis (given in Table 2 and Fig. 3) indicates that (1) the departing fluorine atom is $10-20 \%$ more negatively charged than the other fluorine atoms, (2) the "reacting" (donor) oxygen atom (labeled $\mathrm{O}_{R}$ in Fig. 2) is approximately $20 \%$ more negatively charged than the "shuttling" (acceptor) oxygen (labeled $\mathrm{O}_{\mathrm{S}}$ in Fig. 2), and (3) the two hydrogen being transferred are significantly more positively charged than the other hydrogen atoms, suggesting they are being transferred as protons. These features suggest that the second (shuttling) water molecule may stabilize the reaction by donating electron density, in addition to accepting a proton from the reacting oxygen and donating one to the departing fluorine.

There is also a noticeable change in the orientation of the $\mathrm{HF}$ and $\mathrm{H}_{2} \mathrm{O}$ moieties from the transition state to the product complex (Fig. 2). Using a smaller basis set $(6-31 G(d, p)$ for F, H and $\mathrm{O}$ ) for efficiency, a configuration scan from the transition state to product resulted in a 
potential energy surface showing several minima. Analysis of the energy as a function of the $\mathrm{H}-\mathrm{O}-\mathrm{U}-\mathrm{F}$ dihedral angle between the $-\mathrm{OH}$ group and the departing fluorine is described by a nearly barrierless rotation of the $-\mathrm{OH}$ group through two minima. However, with the more comprehensive $6-31++\mathrm{G}(\mathrm{d}, \mathrm{p})$ basis set, no local minima or rotational barriers were found, and the energy decreased monotonically as the dihedral angle decreased from 180.0 to 0.0 degrees (i.e. from the transition state structure to the product state structure).

Compared to the bimolecular $\left(\mathrm{UF}_{6}+\mathrm{H}_{2} \mathrm{O}\right)$ reaction, the addition of a second water molecule lowers the predicted barrier for the hydrolysis reaction significantly (by $20.7 \mathrm{~kJ} \cdot \mathrm{mol}^{-1}$ ) to $58.9 \mathrm{~kJ} \cdot \mathrm{mol}^{-1}$. Furthermore, in contrast to the single water reaction, the initial two-water reaction has an exothermic enthalpy of reaction $\left(\Delta \mathrm{H}_{298}\right)$ of $-13.9 \mathrm{~kJ} \cdot \mathrm{mol}^{-1}$. The magnitude of the energy barrier for this reaction remains somewhat at odds with experimental observations of spontaneous reaction at ambient conditions. However, the facts that the barrier is lower than that of the bimolecular reaction and that the overall reaction has become exothermic both indicate the interactions of multiple small molecules with each other and $\mathrm{UF}_{6}$ are important during hydrolysis and warrant further study.

\section{Conclusion}

Within the nuclear fuel production industry, quantitative analysis of $\mathrm{UO}_{2} \mathrm{~F}_{2}$ particle growth and its effects on final $\mathrm{UO}_{2}$ product characteristics is frustrated by the lack of fundamental data on $\mathrm{UF}_{6}$ hydrolysis. The work presented here builds on past work and supports ongoing work to clearly determine the details of the mechanisms of the $\mathrm{UF}_{6}$ hydrolysis reaction. The combination of density functional theory with a small-core, scalar relativistic pseudopotential has been used to investigate two trimolecular gas-phase reactions of $\mathrm{UF}_{6}$ with 
water. Both reactions predict the formation of a $\mathrm{UF}_{5} \mathrm{OH}$ intermediate as first suggested

previously. ${ }^{25}$ The computed transition states for both reactions involve interesting shuttling mechanisms: the $2 \cdot \mathrm{UF}_{6}+\mathrm{H}_{2} \mathrm{O}$ hydrolysis reveals a "fluorine-shuttle" mechanism, while the $\mathrm{UF}_{6}+2 \cdot \mathrm{H}_{2} \mathrm{O}$ hydrolysis utilizes a "proton-shuttle" mechanism. The energy barrier and reaction enthalpy of the $2 \cdot \mathrm{UF}_{6}+\mathrm{H}_{2} \mathrm{O}$ trimolecular reaction are predicted to be 69.0 and $+17.9 \mathrm{~kJ} \cdot \mathrm{mol}^{-1}$, respectively, making the reaction more favorable than the bimolecular $\mathrm{UF}_{6}+\mathrm{H}_{2} \mathrm{O}$ reaction, albeit still endothermic. The $\mathrm{UF}_{6}+2 \cdot \mathrm{H}_{2} \mathrm{O}$ hydrolysis reaction is predicted to proceed over a slightly lower energy barrier and have an exothermic reaction enthalpy $\left(58.9\right.$ and $-13.9 \mathrm{~kJ} \cdot \mathrm{mol}^{-1}$, respectively, including ZPE corrections). The magnitude of the energy barrier for the $2 \cdot \mathrm{UF}_{6}+\mathrm{H}_{2} \mathrm{O}$ reaction may be somewhat incongruent with observations of spontaneous reaction at ambient conditions. However, the exothermic nature of the overall reaction and the lowering of the barrier height with respect to the bimolecular reaction both indicate that interactions of more than two molecules are likely important during $\mathrm{UF}_{6}$ hydrolysis. Further study of the $\mathrm{UF}_{6}$ hydrolysis reaction mechanism is warranted to resolve the remaining discrepancies between the predicted mechanisms and experimental observations.

\section{Acknowledgements}

The present work was supported through Contract DE-AC09-08SR 22470 with the U.S. Department of Energy. This report was prepared as an account of work sponsored by an agency of the United States Government. Neither the United States Government nor any agency thereof, nor any of their employees, nor any of their contractors, subcontractors, or their employees, makes any warranty, express or implied, or assumes any legal liability or responsibility for the accuracy, completeness, or any third party's use of the results of such use of any information, 
apparatus, product, or process disclosed, or represents that its use would not infringe privately owned rights. Reference herein to any specific commercial product, process, or service by trade name, trademark, manufacturer, or otherwise does not necessarily constitute or imply its endorsement, recommendation, or favoring by the United States Government or any agency thereof or its contractors or subcontractors. The views and opinions of the authors expressed herein do not necessarily state or reflect those of the United States Government or any agency thereof. Images for this document were prepared using the cheMVP software written by Dr. Andrew C. Simmonett. 


\section{References}

(1) Hou, R. Z.; Mahmud, T.; Prodromidis, N.; Roberts, K. J.; Williams, R. A.;

Goddard, D. T.; Semeraz, T. Ind. Eng. Chem. Res. 2007, 46, 2020.

(2) Klimov, V. D.; Kravetz, Y. M.; Besmelnitzin, A. V. J. Fluorine Chem. 1992, 58, 262.

(3) Wilson, P. W. J. Chem. Soc.-Chem. Commun. 1972, 1241.

(4) Wilson, P. W. J. Inorg. Nucl. Chem. 1974, 36, 303.

(5) Paine, R. T.; Ryan, R. R.; Asprey, L. B. Inorg. Chem. 1975, 14, 1113.

(6) Pickrell, P. W. "Characterization of the solid, airborne materials created by the interaction of UF6 with atmospheric moisture in a contained volume," Report K/PS-144, Oak Ridge Gaseous Diffusion Plant, 1982.

(7) Bostick, W. D.; McCulla, W. H.; Pickrell, P. W.; Branam, D. A. "Sampling and characterization of aerosols formed in the atmospheric hydrolysis of UF6," Report K/PS-5027, Oak Ridge Gaseous Diffusion Plant, 1983.

(8) Bostick, W. D.; McCulla, W. H.; Pickrell, P. W. "Sampling, characterization, and remote sensing of aerosols formed in the atmospheric hydrolysis of uranium hexafluoride," Report K/PS-5042, Oak Ridge Gaseous Diffusion Plant, 1984.

(9) Pickrell, P. W. "Characterization of the solid, airborne materials created by the interaction of UF6 with atmospheric moisture in a contained volume," Report K/PS-915, Oak Ridge Gaseous Diffusion Plant, 1984.

(10) Pickrell, P. W. "Characterization of the solid, airborne materials created when UF6 reacts with moist air flowing in single-pass mode," Report K/PS-1134, Oak Ridge Gaseous Diffusion Plant, 1985. 
(11) Kips, R.; Leenaers, A.; Tamborini, G.; Betti, M.; Van den Berghe, S.; Wellum, R.; Taylor, P. Microsc. microanal. 2007, 13, 156.

(12) Kips, R. S.; Kristo, M. J. J. Radioanal. Nucl. Chem. 2009, 282, 1031.

(13) Otey, M. G.; Ledoux, R. A. J. Inorg. Nucl. Chem. 1967, 29, 2249.

(14) Batista, E. R.; Martin, R. L.; Hay, P. J.; Peralta, J. E.; Scuseria, G. E. J. Chem. Phys. 2004, 121, 2144.

(15) Privalov, T.; Schimmelpfennig, B.; Wahlgren, U.; Grenthe, I. J. Phys. Chem. A 2002, 106, 11277.

(16) Shamov, G. A.; Schreckenbach, G.; Vo, T. N. Chem.-Eur. J. 2007, 13, 4932.

(17) Han, Y. K. J. Comput. Chem. 2001, 22, 2010.

(18) Han, Y. K.; Hirao, K. J. Chem. Phys. 2000, 113, 7345.

(19) Kovacs, A.; Konings, R. J. M. Theochem-J. Mol. Struct. 2004, 684, 35.

(20) Siboulet, B.; Marsden, C. J.; Vitorge, P. Chem. Phys. 2006, 326, 289.

(21) Garcia-Hernandez, M.; Willnauer, C.; Kruger, S.; Moskaleva, L. V.; Rosch, N. Inorg. Chem. 2006, 45, 1356.

(22) Vallet, V.; Wahlgren, U.; Schimmelpfennig, B.; Moll, H.; Szabo, Z.; Grenthe, I. Inorg. Chem. 2001, 40, 3516.

(23) Vallet, V.; Szabo, Z.; Grenthe, I. Dalton Trans. 2004, 3799.

(24) Tsushima, S.; Reich, T. Chem. Phys. Lett. 2001, 347, 127.

(25) Garrison, S. L.; Becnel, J. M. J. Phys. Chem. A 2008, 112, 5453.

(26) Hu, S.-W.; Wang, X.-Y.; Chu, T.-W.; Liu, X.-Q. J. Phys. Chem. A 2008, 112, 8877. 
(27) Hu, S. W.; Wang, X. Y.; Chu, T. W.; Liu, X. Q. J. Phys. Chem. A 2009, 113, 9243.

(28) Armstrong, D. P.; Bostick, W. D.; Fletcher, W. H. Appl. Spectrosc. 1991, 45, 1008.

(29) Sherrow, S. A.; Hunt, R. D. J. Phys. Chem. 1992, 96, 1095.

(30) Morokuma, K.; Muguruma, C. J. Am. Chem. Soc. 1994, 116, 10316.

(31) Gadzhiev, O. B.; Ignatov, S. K.; Razuvaev, A. G.; Masunov, A. E. J. Phys. Chem. A 2009, 113, 9092 .

(32) Slanina, Z. J. Atmos. Chem. 1988, 6, 185.

(33) Pfeilsticker, K.; Lotter, A.; Peters, C.; Bosch, H. Science 2003, 300, 2078.

(34) Scribano, Y.; Goldman, N.; Saykally, R. J.; Leforestier, C. J. Phys. Chem. A 2006, $110,5411$.

(35) van Lenthe, E.; Ehlers, A.; Baerends, E. J. J. Chem. Phys. 1999, 110, 8943.

(36) Douglas, M.; Kroll, N. M. Ann. Phys. 1974, 82, 89.

(37) Nakajima, T.; Hirao, K. J. Chem. Phys. 2000, 113, 7786.

(38) Hay, P. J.; Martin, R. L. J. Chem. Phys. 1998, 109, 3875.

(39) Kuchle, W.; Dolg, M.; Stoll, H.; Preuss, H. J. Chem. Phys. 1994, 100, 7535.

(40) Cao, X. Y.; Dolg, M.; Stoll, H. J. Chem. Phys. 2003, 118, 487.

(41) Kudin, K. N.; Scuseria, G. E.; Martin, R. L. Phys. Rev. Lett. 2002, 89, 266402.

(42) Lee, C. T.; Yang, W. T.; Parr, R. G. Phys. Rev. B 1988, 37, 785.

(43) Becke, A. D. J. Chem. Phys. 1993, 98, 5648.

(44) Frisch, M. J.; Trucks, G. W.; Schlegel, H. B.; Scuseria, G. E.; Robb, M. A.; Cheeseman, J. R.; J. A. Montgomery, J.; Vreven, T.; Kudin, K. N.; Burant, J. C.; Millam, J. M.; 
Iyengar, S. S.; Tomasi, J.; Barone, V.; Mennucci, B.; Cossi, M.; Scalmani, G.; Rega, N.;

Petersson, G. A.; Nakatsuji, H.; Hada, M.; Ehara, M.; Toyota, K.; Fukuda, R.; Hasegawa, J.;

Ishida, M.; Nakajima, T.; Honda, Y.; Kitao, O.; Nakai, H.; Klene, M.; Li, X.; Knox, J. E.;

Hratchian, H. P.; Cross, J. B.; Bakken, V.; Adamo, C.; Jaramillo, J.; Gomperts, R.; Stratmann, R.

E.; Yazyev, O.; Austin, A. J.; Cammi, R.; Pomelli, C.; Ochterski, J. W.; Ayala, P. Y.;

Morokuma, K.; Voth, G. A.; Salvador, P.; Dannenberg, J. J.; Zakrzewski, V. G.; Dapprich, S.;

Daniels, A. D.; Strain, M. C.; Farkas, O.; Malick, D. K.; Rabuck, A. D.; Raghavachari, K.;

Foresman, J. B.; Ortiz, J. V.; Cui, Q.; Baboul, A. G.; Clifford, S.; Cioslowski, J.; Stefanov, B. B.;

Liu, G.; Liashenko, A.; Piskorz, P.; Komaromi, I.; Martin, R. L.; Fox, D. J.; Keith, T.; Al-

Laham, M. A.; Peng, C. Y.; Nanayakkara, A.; Challacombe, M.; Gill, P. M. W.; Johnson, B.;

Chen, W.; Wong, M. W.; Gonzalez, C.; Pople, J. A. Gaussian 03, Revision D.02; Revision D.02

ed.; Gaussian, Inc.: Wallingford, CT, 2004.

(45) Iché-Tarrat, N.; Marsden, C. J. J. Phys. Chem. A 2008, 112, 7632.

(46) de Jong, W. A.; Harrison, R. J.; Nichols, J. A.; Dixon, D. A. Theor. Chem. Acc.

2001, 107, 22.

(47) Ismail, N.; Heully, J. L.; Saue, T.; Daudey, J. P.; Marsden, C. J. Chem. Phys. Lett. 1999, 300, 296.

(48) Perdew, J. P.; Burke, K.; Ernzerhof, M. Phys. Rev. Lett. 1996, 77, 3865.

\section{Legends}

[Insert Figure Legends here] 


\section{Tables}

Table 1: Calculated energy barriers $\left(\Delta \mathrm{E}^{\ddagger}\right)$, reaction energies $\left(\Delta \mathrm{E}_{\mathrm{r}}\right)$, and reaction enthalpies $\left(\Delta \mathrm{H}_{\mathrm{r}}\right)$, all given in $\mathrm{kJ} \cdot \mathrm{mol}^{-1}$, for the initial step of the reactions of $\mathrm{UF}_{6}+\mathrm{H}_{2} \mathrm{O}, \mathrm{UF}_{6}+2 \cdot \mathrm{H}_{2} \mathrm{O}$, and $2 \cdot \mathrm{UF}_{6}+\mathrm{H}_{2} \mathrm{O}$, at the $\mathrm{B} 3 \mathrm{LYP} / \mathrm{SDD} / 6-31++\mathrm{G}(\mathrm{d}, \mathrm{p})$ level of theory, and for comparison at the PBE0/SDD/6-31++G(d,p) level of theory. Non-ZPE-corrected values are given in parentheses.

\begin{tabular}{|c|c|c|c|c|c|c|}
\hline & \multicolumn{2}{|c|}{$\mathbf{U F}_{6}+\mathbf{H}_{2} \mathbf{O}$} & \multicolumn{2}{|c|}{$2 \cdot \mathrm{UF}_{6}+\mathrm{H}_{2} \mathrm{O}$} & \multicolumn{2}{|c|}{$\mathrm{UF}_{6}+2 \cdot \mathrm{H}_{2} \mathrm{O}$} \\
\hline & B3LYP & B3LYP & B3LYP & PBEO & B3LYP & PBEO \\
\hline$\Delta \mathbf{E}^{\ddagger}$ & 78.2 & 76.1 & 69.0 & 62.6 & 58.9 & 56.5 \\
\hline$(\mathbf{0} \mathrm{K})$ & $(87.7)$ & $(85.5)$ & $(75.8)$ & $(69.1)$ & $(67.0)$ & $(64.8)$ \\
\hline$\Delta \mathbf{E}_{\mathbf{r}}$ & +16.7 & +17.2 & +17.3 & +19.4 & -12.6 & -11.7 \\
\hline$(\mathbf{0} \mathrm{K})$ & $(+21.0)$ & $(+22.1)$ & $(+24.1)$ & $(+26.3)$ & $(-7.6)$ & $(-6.0)$ \\
\hline $\begin{array}{l}\Delta H_{r} \\
(298 \mathrm{~K})\end{array}$ & +15.7 & +16.5 & +17.9 & +20.0 & -13.9 & -12.9 \\
\hline
\end{tabular}

Table 2: Computed Mulliken charge values for selected atoms of the $\mathrm{UF}_{6}+2 \cdot \mathrm{H}_{2} \mathrm{O}$ pre-reactive, transition state, and product complexes.

\begin{tabular}{lccc}
\hline & $\begin{array}{c}\text { Pre-reactive } \\
\text { Complex }\end{array}$ & $\begin{array}{c}\text { Transition State } \\
\text { Complex }\end{array}$ & $\begin{array}{c}\text { Product } \\
\text { Complex }\end{array}$ \\
\hline \hline Reacting Fluorine & -0.48 & -0.58 & -0.41 \\
Donor Oxygen & -0.80 & -0.93 & -0.80 \\
Acceptor Oxygen & -0.75 & -0.75 & -0.75 \\
Reacting Hydrogen & +0.40 & +0.58 & +0.39 \\
Shuttled Hydrogen & +0.46 & +0.50 & +0.46
\end{tabular}




\section{Figures}

Figure 1. Reactant, transition state, and product configurations for two uranium hexafluoride molecules reacting with one water molecule, values given in $\AA$.

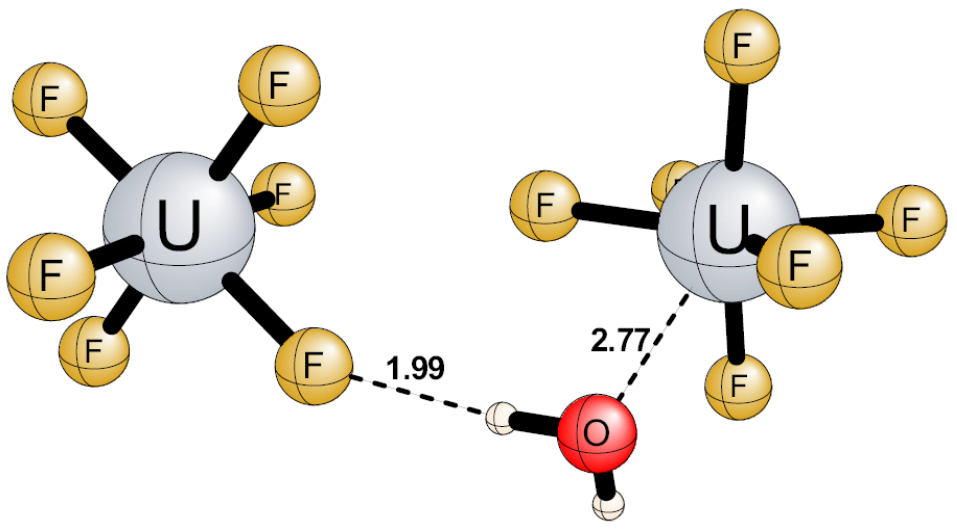

(a) Reactant

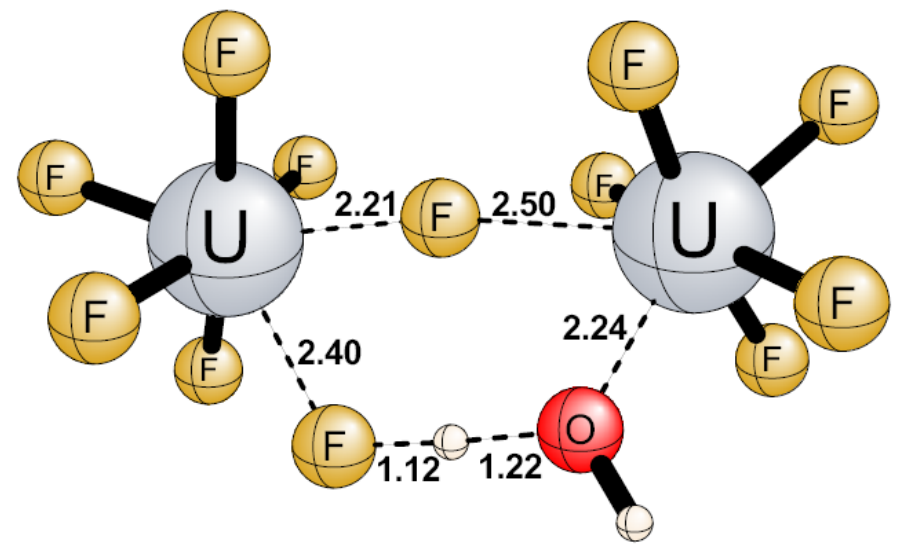

(b) Transition State

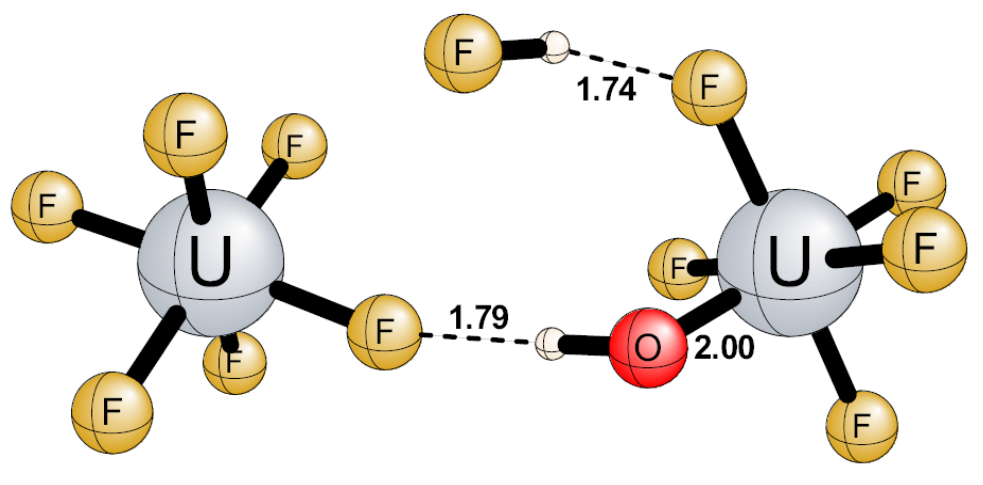

(c) Product 
Figure 2. Reactant, transition state, and product configurations for one uranium hexafluoride molecule reacting with two water molecules, values given in $\AA$.

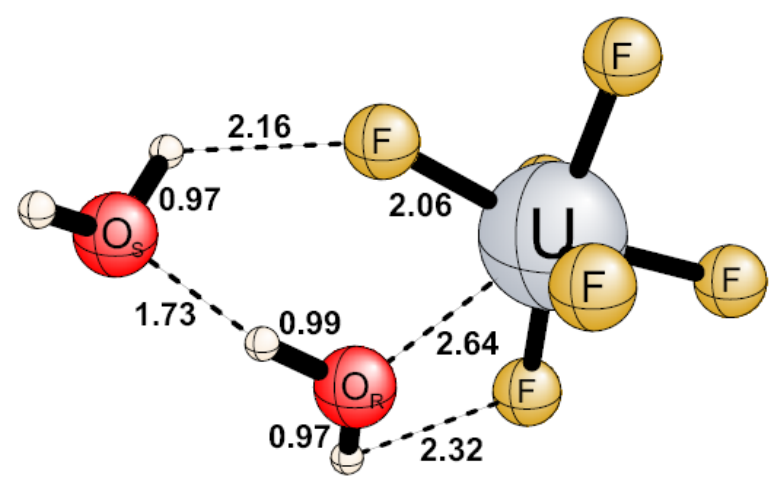

(a) Reactant

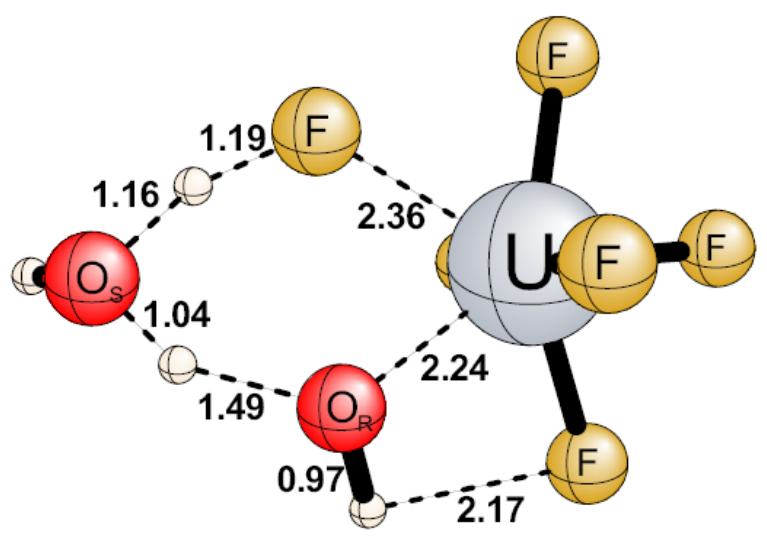

(b) Transition State

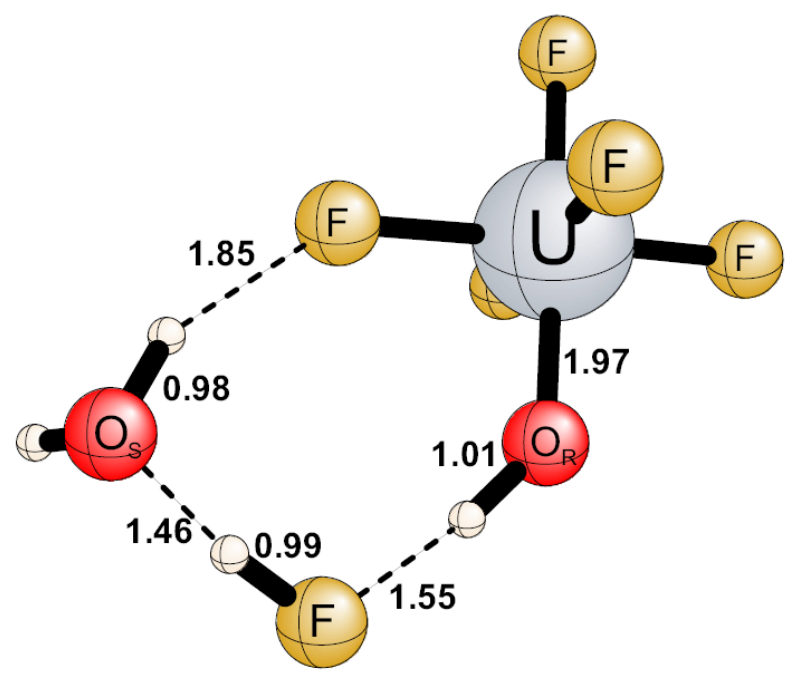

(c) Product 
Figure 3. Reactant, transition state, and product Mulliken charge values for one uranium hexafluoride molecule reacting with two water molecules.

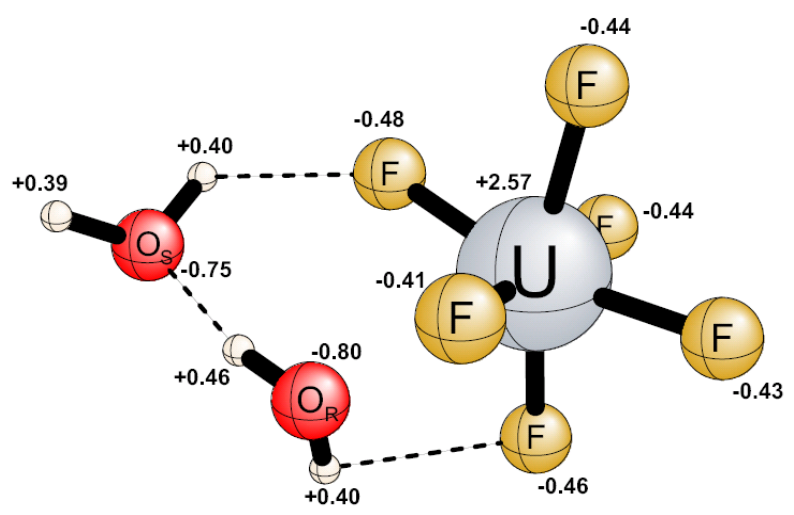

(a) Reactant

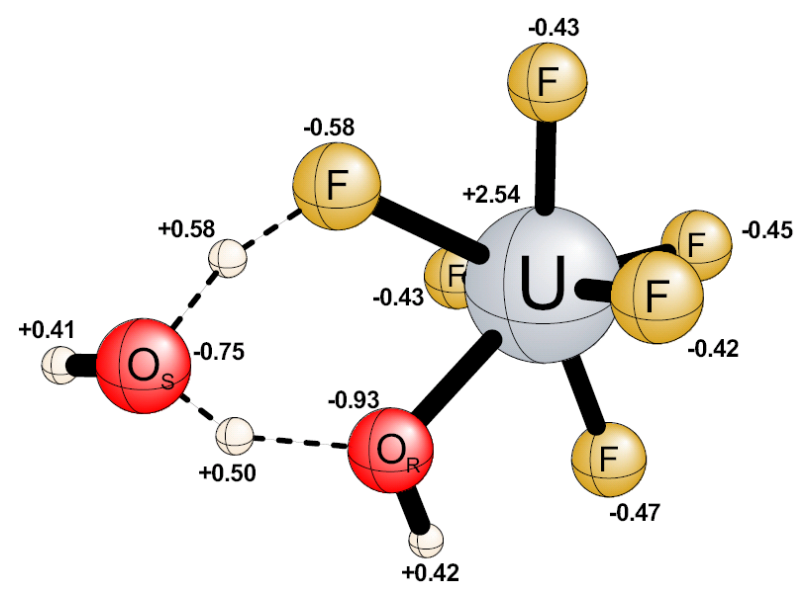

(b) Transition State

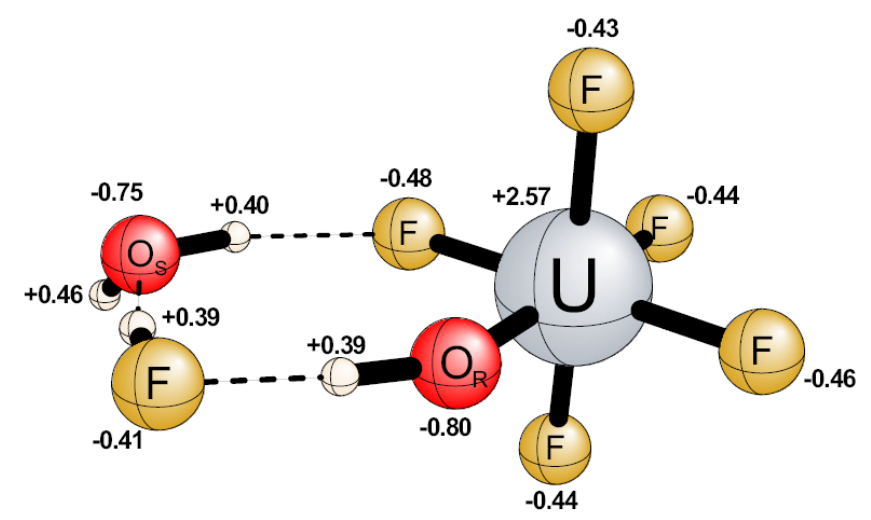

(c) Product 
Figure 4. Calculated energies $\left(\mathrm{kJ} \cdot \mathrm{mol}^{-1}\right)$ for the $\mathrm{UF}_{6}+2 \cdot \mathrm{H}_{2} \mathrm{O}$ reaction path at the B3LYP/SDD/6-31++G(d,p) level of theory, with (without) ZPE corrections.

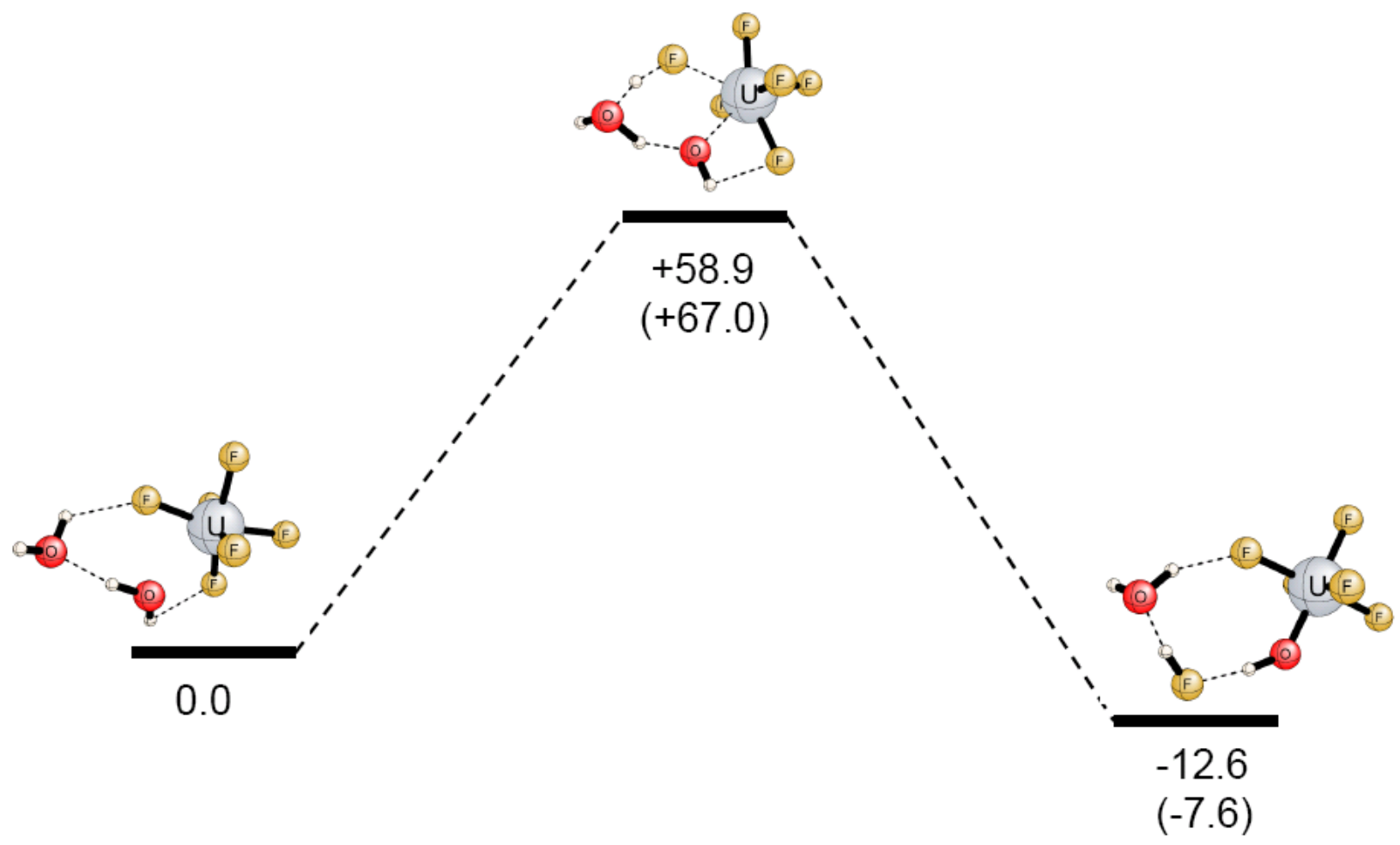


Figure 5. Calculated energies $\left(\mathrm{kJ} \cdot \mathrm{mol}^{-1}\right)$ for the $2 \cdot \mathrm{UF}_{6}+\mathrm{H}_{2} \mathrm{O}$ reaction path at the B3LYP/SDD/6-31++G(d,p) level of theory, with (without) ZPE corrections.

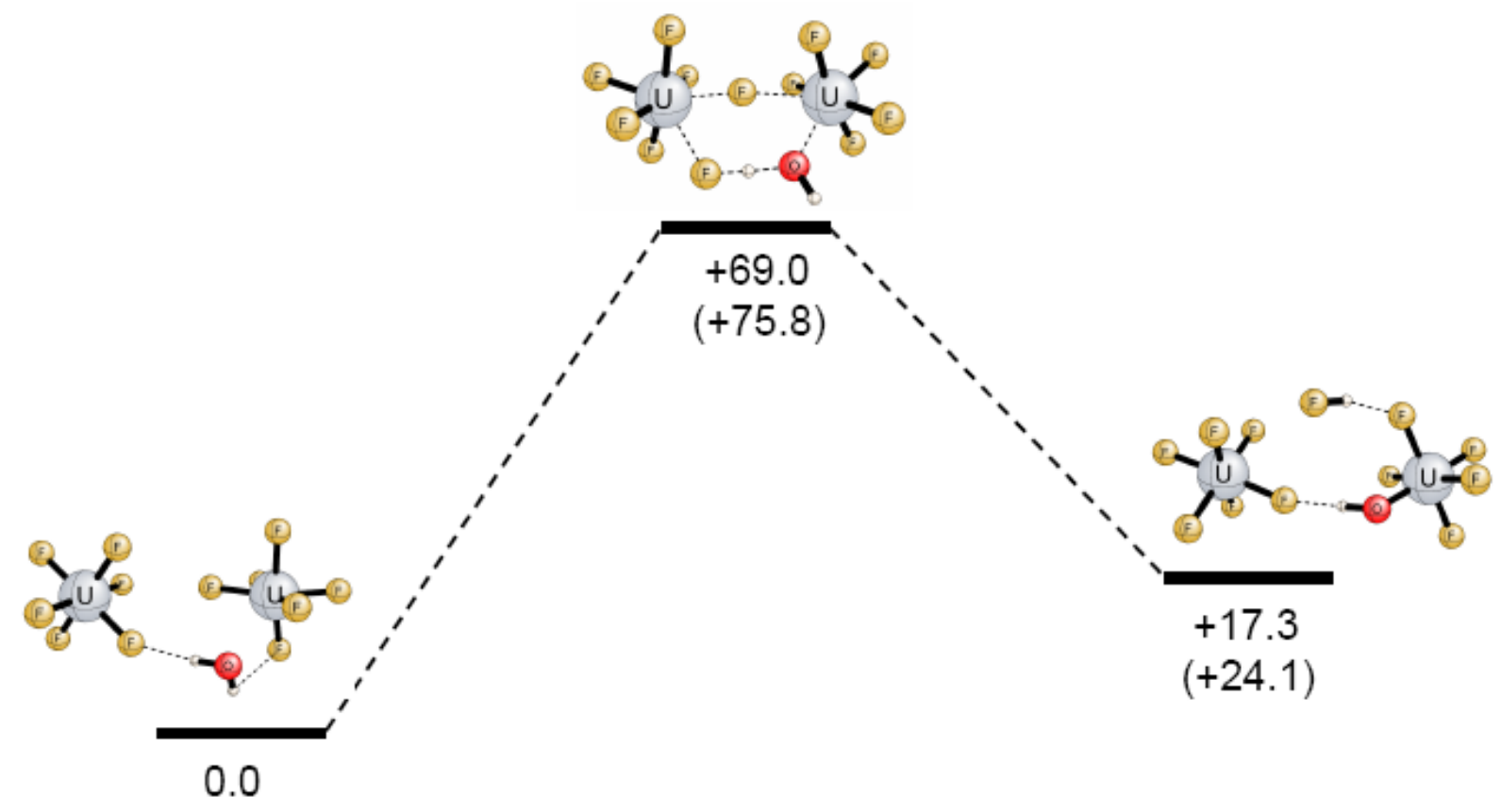


Table of Contents Figure
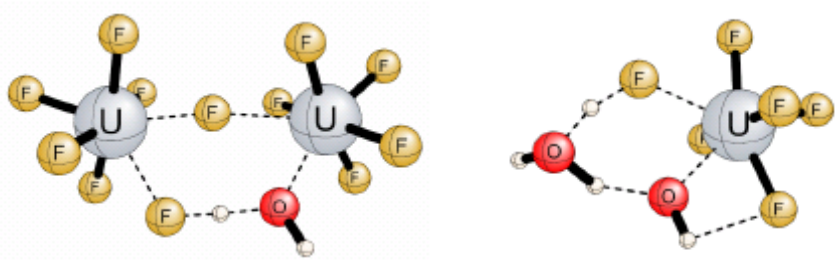